Revista Eletrônica do Mestrado em Educação Ambiental

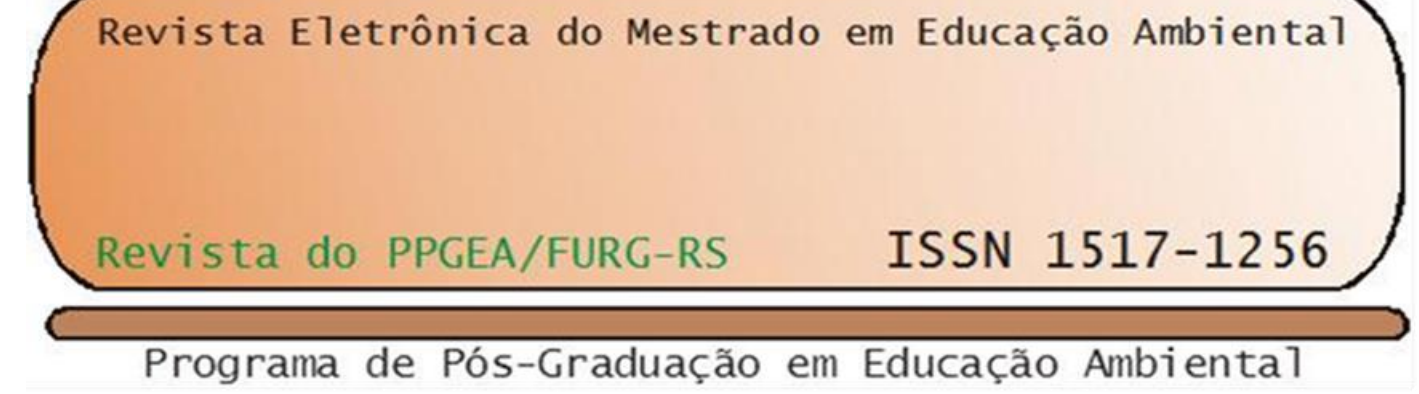

\title{
Paulo Freire e Maurice Tardif: um diálogo de referências para fortalecer a articulação universidade escola na perspectiva da formação com educadores/as
}

Ana Lúcia Souza de Freitas ${ }^{1}$

\begin{abstract}
Resumo: O estudo põe em diálogo as referências de Paulo Freire e Maurice Tardif no âmbito da formação de educadores. Apresenta inicialmente um breve estudo bibliográfico sobre cada um dos autores, enfatizando a reflexão crítica de ambos sobre o distanciamento entre conhecimento teórico e conhecimento prático nos cursos de formação. O estudo bibliográfico realizado permitiu vislumbrar a complementaridade dos autores no que se refere à valorização do conhecimento prático e ao reconhecimento dos/as educadores/as como sujeitos de conhecimento, bem como quanto ao potencial formativo da articulação universidade escola. Com base nos estudos realizados, compartilha-se a compreensão acerca da reciprocidade das ações de pesquisar o ensino e ensinar por meio da pesquisa como um princípio para problematizar as relações entre universidade e escola, na perspectiva da formação com educadores/as.
\end{abstract}

Palavras-chave: Paulo Freire. Maurice Tardif. Formação com educadores.

\section{Paulo Freire and Maurice Tardif: a dialogue of references to strengths the articulation university school under the perspective of education with teachers}

\begin{abstract}
The study proposes a dialogue to Paulo Freire and Maurice Tardif's references concerning teachers' education. First, it presents a brief bibliographic study about each author, highlighting the critical reflection of both authors about the distance between theoretical and practical knowledge regarding teachers' education. The bibliographic study has allowed us to get a glimpse of the complementarity of the authors concerning the valorization of the practical knowledge and the recognition towards teachers as subjects of knowledge as well as the formative potential of the articulation university school. It is shared, based on the studies carried out, the comprehension on the reciprocity of the actions when researching teaching and when teaching through research as a principle to problematize the relationships between university and school under the education with teachers perspective.
\end{abstract}

Keywords: Paulo Freire. Maurice Tardif. Education with teachers.

\footnotetext{
${ }^{1}$ Doutora em Educação com Pós Doutorado em Pedagogia Crítica pela Liverpool Hope University. Professora e Pesquisadora no Programa de Mestrado Profissional em Gestão Educacional. UNISINOS. Email: anafr@unisinos.br
} 


\section{Introdução}

O texto põe em diálogo as referências de Paulo Freire e Maurice Tardif para ratificar o valor dos saberes da experiência profissional docente no âmbito da formação com educadores. Toma como ponto de partida duas afirmações, feitas por outros autores, para justificar a reflexão a que se propõe. A primeira afirmação, feita há quase duas décadas por Francisco Imbernón (2000), no contexto de sua reflexão acerca dos desafios da educação no século XXI; a segunda, também feita há mais de uma década por Boaventura de Sousa Santos (2005), em sua crítica à universidade. Tais afirmações são reveladoras da historicidade do tema, bem como de sua relevância.

A afirmação de Francisco Imbernón diz respeito à sua preocupação com o fato de que "muitos dos postulados vanguardistas avançaram mais no terreno das ideias do que no das práticas alternativas" (IMBERNÓN, 2000, p.79), ou seja: o autor refere-se à fragilidade da repercussão da teoria crítica no âmbito da práxis em instituições concretas, convertidas em experiências comunicáveis. No contexto de sua reflexão, destaca a importância de dois tipos de olhares: "um primeiro olhar imediato, próximo, de curto alcance, um olhar que nos ajuda a resolver esses problemas cotidianos que chegam a nos obcecar e não nos permitem levantar os olhos" (op. cit. p.77) e um segundo olhar, voltado para um exercício de amplitude e profundidade que

[...] mesmo assumindo o risco do engano, do fatalismo ou da fantasia, pode ajudar-nos a avaliar o que obtivemos no passado, o que soubemos construir no presente, o que podemos projetar para o futuro, o que desejamos construir a curto e médio prazos e, principalmente, que mecanismos colocaremos em funcionamento para realizar estes desejos (op. cit. p.77-78).

De modo complementar, a afirmação de Boaventura de Sousa Santos apresenta uma "provoc-ação", problematizando o sentido do que se faz na universidade:

Quem trabalha hoje na universidade sabe que as tarefas universitárias estão dominadas pelo curto prazo, pelas urgências do orçamento, da competição entre faculdades, do emprego dos licenciados, etc. $\mathrm{Na}$ gestão destas urgências florescem tipos de professores e de condutas que pouco préstimo ou relevância teriam se, em vez de urgências, fosse necessário intensificar e potenciar as emergências onde se anuncia o longo prazo (SANTOS, 2005, p.115).

Os referidos autores são tomados como referência para justificar a reflexão proposta neste momento por considerar que suas preocupações ainda são representativas - pelo menos em parte - das práticas educativas na escola e na universidade, 26 Rev. Eletrônica Mestr. Educ. Ambient. E-ISSN 1517-1256, Edição especial XIX Fórum de Estudos: Leituras de Paulo Freire, p. 25-39, junho, 2017. 
circunstanciadas num quadro social marcado pela "desregulamentação social e econômica, as ideias e práticas neoliberais, a tão falada globalização ou mundialização, os indicadores de desempenho para medir a qualidade educativa, a falsa autonomia da educação e o avanço do gerencialismo educativo" (IMBERNÓN, 2011, p.38).

Em consonância com os referidos autores, a reflexão que o texto apresenta pretende ir além das urgências do cotidiano, propondo um olhar que não se reduza ao curto alcance, mas que se disponha a problematizar as relações entre universidade e escola no âmbito da formação com educadores/as, apresentando a seguinte questão: como se estabelece o diálogo entre conhecimento teórico e conhecimento prático entre educadores/as que atuam na escola e educadores/as que atuam na universidade? Ao propor um olhar de longo alcance, não se pretende esgotar a reflexão, mas, ao contrário, destacar a necessidade de seguir, coletivamente, construindo a compreensão sobre o tema em sua amplitude e profundidade. Assim como Imbernón (2000), compreende-se que desenvolver o olhar em profundidade pode contribuir para orientar a tomada de decisão referente às questões de curto prazo que se apresentam no cotidiano da universidade e da escola, bem como nas relações pessoais/institucionais entre os/as educadores/as que nelas trabalham.

É nesse sentido que o texto apresenta o diálogo entre Paulo Freire e Maurice Tardif, chamando atenção para o distanciamento entre conhecimento teórico e conhecimento prático no âmbito da formação de professores e destacando a necessidade de avançarmos, tal como propõe Clermont Gauthier (1998) em relação a um repertório de conhecimentos próprios ao ensino, tendo em vista a profissionalização da docência. Segundo o autor, a pesquisa em educação, ao tematizar os saberes necessários ao ensino, contribui para a superação de dois obstáculos fundamentais: de um lado, o exercício da atividade docente que não leva em conta os saberes que lhe são inerentes, e de outro, a produção de ciências da educação que não levam em conta as condições concretas do exercício do magistério. Trata-se de compreender tais obstáculos como a dupla face de um mesmo problema: a falta de diálogo entre conhecimento teórico e conhecimento prático, fragilizando a constituição de um conhecimento profissional socialmente relevante como perspectiva da formação docente. Todavia, avançar nesta direção requer problematizar as relações estabelecidas entre universidade e escola.

Com o intuito de contribuir em relação a este tema/problema, apresenta-se a seguir o estudo a seguir, organizado em três partes. As duas primeiras partes apresentam um breve estudo bibliográfico sobre cada um dos autores, enfatizando a reflexão crítica 
de ambos sobre o distanciamento entre conhecimento teórico e conhecimento prático no âmbito da formação de educadores/as. Na terceira parte, destaca-se a complementaridade dos autores no que se refere à valorização do conhecimento prático, ao reconhecimento dos/as educadores/as como sujeitos de conhecimento e ao potencial formativo da articulação universidade escola. Nas considerações finais, compartilha-se a sistematização de algumas ideias-força que anunciam os benefícios da articulação universidade escola, no que diz respeito ao fortalecimento dos saberes docentes em seu potencial educativo transformador/libertador. Com base nesta compreensão, reitera-se a proposição acerca da formação com educadores/as como forma de expressar o princípio da reciprocidade entre as ações de pesquisar o ensino e de ensinar por meio da pesquisa enquanto referência para problematizar as ações entre universidade e escola, na perspectiva da horizontalidade das relações estabelecidas.

\section{Paulo Reglus Neves Freire: uma referência da teorização a partir da própria prática}

Paulo Reglus Neves Freire (1921 - 1997) representa um marco na história da educação brasileira e de outros países. A referência ao nome do autor por extenso tem o intuito de chamar atenção para o fato de que, tal como seu nome próprio, há muitos aspectos pouco conhecidos e/ou reconhecidos de sua obra. Seu pensamento representa uma das tendências pedagógicas no campo da pedagogia progressista: a educação libertadora. Em oposição à educação bancária, propõe uma prática educativa conscientizadora a favor dos oprimidos. A partir de suas primeiras experiências com educação de adultos, a experiência do exílio e o contato com outros países transformaram-no num cidadão do mundo sem nunca esquecer suas raízes de cidadão pernambucano (FREITAS, 2014).

Sua contribuição para a profissionalização da docência diz respeito à crítica à atuação docente fundada em uma racionalidade exclusivamente técnica, anunciando sua compreensão acerca da docência como produção de conhecimento, bem como da escola como um importante espaço de formação. Segundo Freire, “A escola não é só um espaço físico. É um clima de trabalho, uma postura, um modo de ser" (FREIRE, 1991, p.16).

Merece destaque, entre os aspectos abordados quanto à profissionalização da docência, sua argumentação acerca da recusa da identificação da figura da professora com a da tia. Na obra Professora, sim; tia não, Freire chama atenção para o fato de que não é possível, à professora, “desconhecer as implicações escondidas na manha 
ideológica que envolve a redução da condição de professora à de tia" (FREIRE, 1993b, p.26). Entre elas, adocicar sua capacidade de luta, ou de desafiar seus alunos, desde pequenos, a compreender a necessidade de coerência entre teoria e prática, assim como a não neutralidade do discurso.

As relações estabelecidas entre contexto teórico e contexto concreto no campo da formação de professores é também um tema presente no pensamento de Paulo Freire que merece destaque no âmbito da profissionalização da docência. Segundo ele, a questão que se coloca é "como do contexto teórico "tomamos distância" de nossa prática e nos tornamos epistemologicamente curiosos para então apreendê-la em sua razão de ser" (FREIRE, 199b3, p.104). Todavia, faz a crítica às relações estabelecidas na universidade, considerando que

[...] nossa experiência na universidade tende a nos formar à distância da realidade. Os conceitos que estudamos na universidade podem trabalhar no sentido de nos separar da realidade concreta à qual, supostamente, se referem. Os próprios conceitos que usamos na nossa formação intelectual e em nosso trabalho estão fora da realidade, muito distantes da sociedade concreta. Em última análise, tornamo-nos excelentes especialistas, num jogo intelectual muito interessante, o jogo dos conceitos! É um "balé dos conceitos" (FREIRE; SHOR, 1986, p.131).

Segundo ele, "a formação intelectual do educador o leva a pensar a partir do abstrato, dicotomizado do concreto" (FREIRE, 1993a, p.53). Inversamente, na linguagem popular se descreve o objeto e não o seu conceito. E exemplifica:

Se se pergunta a um estudante universitário o que é favela, sua tendência é, usando o verbo ser, verbo conotativo, descrever o conceito de favela. Se se faz a mesma pergunta a um favelado, sua tendência é descrever a situação concreta da favela, usando o verbo ter na negativa. "Na favela não tem água, farmácia." (op. cit.)

Assim, Freire nos mobiliza a pensar acerca da necessidade de que se estabeleça uma nova relação entre conhecimento teórico e conhecimento prático no âmbito da formação de professores. Nesse sentido, sua própria experiência como educador e, posteriormente, como gestor na secretaria municipal de educação em São Paulo, é reveladora da possibilidade de articulação teórico-prática, gerada no intenso processo de reflexão sobre suas vivências.

Sua produção teórico-crítica, ao revelar o desenvolvimento de uma rigorosidade metódica própria, em sua experiência de "gestação das ideias" (FREIRE, 1992), sugere caminhos à auto-organização de seus/uas leitores/as, de modo a potencializar o 
conhecimento gerado nas e a partir das experiências cotidianas. Teorizar a partir da prática é, pois, um importante legado à formação com educadores/as (FREITAS, 2001; 2014).

Paulo Freire se faz referência da teorização a partir da própria prática, exercendose como sujeito do conhecimento, em coerência à sua argumentação de que "ensinar não é transferir conhecimento, mas criar as possibilidades para a sua produção ou sua construção (FREIRE, 1996, p.25)", ou seja, trata-se de sua compreensão/ação acerca da indissociabilidade da relação ensino-pesquisa, ao considerar que "o que há de pesquisador no professor não é uma qualidade ou uma forma de ser ou de atuar que se acrescente à de ensinar. Faz parte da natureza da prática docente a indagação, a busca a pesquisa" (op. cit. p.32).

A obra de Paulo Freire se faz testemunho da criticidade exercida no processo de pesquisar a prática educativa, mediante a assunção de sua natureza política. A leitura de sua obra permite identificar uma prática crítico-reflexiva exercida em diferentes níveis, potencializando a tomada de consciência do conhecimento prático. Trata-se de importante referência para que educadores/as se assumam como sujeitos de conhecimento, investigadores/as da própria prática, bem como para o desenvolvimento da cultura da pesquisa associada à formação docente. Neste sentido, urge atualizar o debate, com base no pensamento freireano, acerca das relações entre politicidade e rigorosidade no âmbito da formação com educadores/as, tendo em vista o fortalecimento das autorias de educadores/as que atuam na universidade, na escola e em outros espaços educativos.

\section{Maurice Tardif: uma referência na investigação com os professores de profissão}

Maurice Tardif, pesquisador canadense, é professor titular na Universidade de Montreal, no Canadá, onde dirige um importante centro de pesquisa sobre a profissão docente. Sua obra tem sido referência no âmbito da pesquisa e formação de professores no Brasil. Em 2000, participou do X ENDIPE - Encontro Nacional de Didática e Prática do Ensino - realizado no Rio de Janeiro, cujo como tema central foi Ensinar e aprender sujeitos, saberes, espaços e tempos.

$\mathrm{Na}$ ocasião, participou de uma mesa-redonda sobre Os professores enquanto sujeitos do conhecimento: subjetividade, prática e saberes no magistério, cuja reflexão, posteriormente publicada, trouxe importantes contribuições ao debate da pesquisa e formação de professores. Todavia, a obra Saberes docentes e formação profissional - 
publicada em 2002 - trouxe novos elementos para ampliar a compreensão acerca de suas contribuições para a formação crítico-reflexiva de professores/as pesquisadores/as.

O cerne de sua contribuição consiste em problematizar os saberes necessários à docência, partindo do pressuposto de que o saber disciplinar - que diz respeito ao conteúdo a ser ensinado - é elemento necessário, mas não suficiente à profissão docente. Trata-se de compreender que o ato de ensinar não se reduz à sua dimensão técnica, pois "Ensinar é, obrigatoriamente, entrar em relação com o outro. Ora, para que essa relação se estabeleça, é preciso que o professor e os alunos se entendam minimamente" (TARDIF, 2002b, p.222). Segundo o autor, o trabalho docente se caracteriza "por um alto grau de indeterminação na realização do processo de trabalho, o que exige dos profissionais uma construção de julgamentos em situações de ação" (op. cit. p.249).

Tais compreensões orientam as investigações de Maurice Tardif, cuja produção contribui significativamente para a constituição de um repertório de conhecimentos próprios ao ensino, anunciando a complexidade do conhecimento profissional docente. $\mathrm{O}$ autor contribui para a compreensão de que os saberes docentes são heterogêneos e plurais, oriundos de diversas fontes, classificando-os em cinco tipos: o saber cultural, o saber profissional, o saber disciplinar, o saber curricular e o saber experiencial.

O saber cultural diz respeito aos saberes oriundos das experiências familiares e escolares que trazem em si imagens acerca da docência e do ensino herdadas em função de uma história de vida em uma cultura particular; o saber profissional diz respeito às aprendizagens provenientes da formação inicial; o saber disciplinar aos conhecimentos específicos de uma área de atuação; e o saber curricular diz respeito aos programas escolares propriamente ditos. Por sua vez, o saber experiencial, compreendido como o saber oriundo da atuação profissional propriamente dita, merece destaque no pensamento de Tardif. Sua obra se associa à produção de outros/as autores/as que, assim como Donald Schön (2000), perseguem a constituição de uma nova epistemologia da prática profissional docente, dando visibilidade ao "conjunto dos saberes utilizados realmente pelos profissionais em seu espaço de trabalho cotidiano para desempenhar todas as suas tarefas" (TARDIF, 2002b, p.255).

Com este intuito, Maurice Tardif desafia a reinvenção das relações estabelecidas entre universidade e escola, argumentando que "a produção dos saberes sobre o ensino não pode ser mais o privilégio exclusivo dos pesquisadores, e que estes devem reconhecer que os professores também possuem saberes que são diferentes dos conhecimentos universitários" (2002a, p.122). Em seu entendimento, um dos maiores 
problemas é justamente o de que "os pesquisadores se interessam muito mais pelo que os professores deveriam ser, fazer e saber do que pelo que eles são, fazem e sabem realmente" (TARDIF, 2002b, p.259).

No desenvolvimento de sua reflexão, Tardif identifica dois problemas epistemológicos do modelo universitário de formação: (1) “ele é idealizado segundo uma lógica disciplinar e não segundo uma lógica profissional centrada no estudo das tarefas e realidades do trabalho dos professores" (op. cit. p.271); e (2) "esse modelo trata os alunos como espíritos virgens e não leva em consideração suas crenças e representações anteriores a respeito do ensino (op. cit. p.273). Em síntese, diz respeito ao problema da desvinculação entre o conhecimento teórico o conhecimento prático no âmbito da formação de professores. Diante do compromisso de reconstituir os fundamentos epistemológicos da profissão, tendo em vista a superação deste distanciamento, Tardif anuncia tarefas que representam possibilidades promissoras e campo de trabalho para os pesquisadores universitários. Entre elas, introduzir dispositivos de formação que não sejam exclusivamente ou principalmente regidos pela lógica do meio universitário e que sejam reconhecidos pelos professores como úteis para sua atuação profissional.

$\mathrm{Na}$ atualidade de sua reflexão, Tardif analisa a diversidade dos aspectos que envolvem o processo de profissionalização docente, destacando a amplitude deste campo de investigação. Em suas palavras:

Trinta anos mais tarde, o que resta da profissionalização e da vontade política de construir uma Knowledge base? Após milhares de pesquisas sobre a questão, conhecemos melhor agora o que é o conhecimento dos professores? Responder a essas questões não é nada fácil (TARDIF, 2013, p.17).

Como conceber uma verdadeira profissionalização diante de obstáculos como a precarização das escolas públicas, a mercantilização da educação, a concorrência desigual, a proletarização de grande parte dos professores, a desigualdade das condições do trabalho docente em diferentes níveis de ensino, entre outros? É neste contexto diverso e adverso que a investigação com os professores de profissão, na perspectiva proposta por Maurice Tardif, representa tanto um permanente desafio à inovação nas relações estabelecidas entre educadores/as que atuam na universidade e na escola, quanto uma possibilidade de avançar em relação à profissionalização da docência. 


\section{Freire e Tardif: um diálogo entre referências para a formação com educadores/as}

O estudo do pensamento de Paulo Freire e de Maurice Tardif permite vislumbrar uma identidade de perspectivas entre suas proposições no âmbito da formação de professores. Neste trabalho, a proximidade entre o pensamento dos autores será apresentada considerando três aspectos, abordados na continuidade do texto: a valorização do conhecimento prático, o reconhecimento dos/as educadores/as como sujeitos de conhecimento, e o potencial formativo da articulação universidade escola. A compreensão de tais aspectos, com base na complementaridade do pensamento dos autores, fundamenta a proposição da formação com educadores/as como uma perspectiva a ser perseguida na qualidade das relações estabelecidas entre universidade e escola.

$\mathrm{O}$ primeiro aspecto diz respeito à proximidade dos autores quanto ao seu posicionamento em relação à valorização do conhecimento prático. A compreensão da referida proximidade leva em conta que ambos expressam, de modo particular, sua contribuição para a epistemologia da prática, em consonância com o que propõe Donald Schön (2000), ao valorizar conhecimento prático, fazendo distinção de quatro noções complementares: o conhecimento na ação; a reflexão na ação; a reflexão sobre a ação e a reflexão sobre a reflexão na ação.

Maurice Tardif expressa seu reconhecimento do valor dos saberes experienciais, tendo como pressuposto a convicção de que "os professores de profissão possuem saberes específicos que são mobilizados, utilizados e produzidos por eles no âmbito de suas tarefas cotidianas" (TARDIF, 2002b, p.228). Compreende que os saberes profissionais docentes dizem respeito a uma gama de saberes, não exclusivamente acadêmicos, mas oriundos de diversas fontes. Dedica-se à investigação dos saberes dos professores de profissão, tornando-se referência do reconhecimento e da valorização da pluralidade dos saberes docentes, marcados, entre outras peculiaridades que os definem, por sua temporalidade, heterogeneidade e personalização.

Por sua vez, Paulo Freire valoriza os saberes de experiência feitos, argumentando "sua discordância com a visão cientificista que supervaloriza a ciência e menospreza o senso comum" (FREITAS, 2008, p.374). Compreende que o saber de experiência feito é revelador da visão de mundo dos sujeitos envolvidos nos processos de ensinar e de aprender e, em função disso, concebe o saber de experiência feito como ponto de partida da prática educativa. Sobretudo, Paulo Freire convida educadores/as a tomarem como objeto de estudo a própria prática e a observarem os saberes nela gestados. A este respeito, a obra Pedagogia da Autonomia, tendo como subtítulo "saberes necessários à 
prática educativa" (FREIRE, 1996), é bastante representativa da amplitude do pensamento do autor acerca dos saberes docentes.

O segundo aspecto refere-se à proximidade dos autores quanto ao reconhecimento dos/as educadores/as como sujeitos de conhecimento. Os professores enquanto sujeitos de conhecimento é um subtítulo atribuído por Maurice Tardif em sua obra Saberes docentes e formação profissional, chamando atençãom para a sua compreensão de que considerar os professores como sujeitos de conhecimento, permite renovar as visões vigentes a respeito do ensino. Segundo ele,

[...] um professor de profissão não é somente alguém que aplica conhecimentos produzidos por outros, não é somente um agente determinado por mecanismos sociais: é um ator no sentido forte do termo, isto é, um sujeito que assume sua prática a partir dos significados que ele mesmo lhe dá, um sujeito que possui conhecimentos e um saber-fazer provenientes de sua própria atividade e a partir dos quais ele a estrutura e orienta (TARDIF, 2002b, p.229).

Como consequências desta compreensão, Tardif argumenta a necessidade de recolocar a subjetividade dos professores no centro das pesquisas sobre o ensino, bem como de se repensar as relações entre teoria e prática, reconhecendo os professores que atuam na escola como sujeitos, atores que desenvolvem teorias, conhecimentos e saberes sobre a sua própria ação. A concepção de Paulo Freire acerca do professor pesquisador alinha-se à compreensão de Tadif acerca dos professores como sujeitos de conhecimento. Diante do amplo debate a este respeito na década de 90, Freire assim se posiciona:

Fala-se hoje, com insistência, no professor pesquisador. No meu entender o que há de pesquisador no professor não é uma qualidade ou uma forma de ser ou de atuar que se acrescente à de ensinar. Faz parte da natureza da prática docente a indagação, a busca a pesquisa. $\mathrm{O}$ de que se precisa é que, em sua formação permanente, o professor se perceba e se assuma, porque professor, como pesquisador (FREIRE, 1996, p.32).

A concepção freireana do educador/a como pesquisador/a, está em consonância com a concepção de Tardif no que se refere à presença do sujeito que ensina, bem como à própria concepção de ensino, que não se reduz ao conhecimento existente. Nas palavras de Freire, "Ensinar, aprender e pesquisar lidam com esses dois momentos do ciclo gnosiológico: o em que se ensina e se aprende o conhecimento já existente e o em que se trabalha a produção do conhecimento ainda não existente" (op. cit., p.31). Para Tardif, "o 
ensino não é mais uma atividade que se executa, mas uma prática na qual devemos pensar, que devemos problematizar, objetivar, criticar, melhorar (TARDIF, 2013, p.11).

O terceiro aspecto revelador da proximidade do pensamento de Paulo Freire e Maurice Tardif diz respeito à compreensão de ambos acerca do potencial formativo da articulação universidade escola e, em função disso, sua contundente crítica às relações tradicionalmente estabelecidas, bem como seu compromisso com proposições que reconheçam os professores como sujeitos do conhecimento. No que se refere à pesquisa universitária, Tardif considera que a produção do conhecimento sobre o ensino “começará a progredir a partir do momento em que ela reconhecer que não produz uma teoria sobre uma prática, mas que ela mesma é uma prática referente a atividades (ou seja, ensinar) e atores (ou seja, os professores) que dispõem de seus próprios saberes e de seus próprios pontos de vista" (TARDIF, 2002b, p.238). De igual modo, argumenta a importância da criação de "novos dispositivos de formação nos quais os professores de profissão sejam considerados, de fato e de direito, formadores dos futuros professores" (op. cit., p. 240).

Na mesma direção, Paulo Freire acredita que "a aproximação da universidade com a escola permite que a própria universidade se aproprie de um conhecimento da realidade que a fará repensar o seu ensino e a sua pesquisa" (FREIRE, 1991, p.81-82). Em sua experiência como secretário municipal de educação em São Paulo, buscou a colaboração de professores universitários, sem ônus para o município, para discutir sobre a necessária mudança da escola. Segundo ele, a universidade tem uma responsabilidade social a cumprir junto à escola básica, tanto no que diz respeito ao avanço do conhecimento nas diversas áreas, quanto nas questões relativas à formação dos profissionais que atuam nas redes de ensino (FREIRE, 1991).

Todavia, assim como Tardif propõe que se privilegie o estudo dos saberes dos atores em seu contexto real de trabalho, em situações concretas de ação, Paulo Freire, em seu trabalho cmo gestor, dá destaque à formação que "se faz no âmbito da própria escola, com pequenos grupos de educadores ou com grupos ampliados, resultante de agrupamentos de escolas próximas" (FREIRE, 1991, p.81). Em síntese, ambos têm contribuições relevantes para o redimensionamento das relações universidade escola no âmbito da formação de professores, valorizando a escola como um lugar de produção de conhecimento.

Com base na complementaridade do pensamento de Paulo Freire e Maurice Tardif, fundamenta-se a proposição da formação com educadores/as como uma 
perspectiva a ser perseguida, buscando superar a assimetria das relações estabelecidas entre universidade e escola. Esta é uma perspectiva que desafia a proposição de práticas inovadoras, tendo em vista o fortalecimento dos/as educadores/as que atuam na universidade e na escola.

\section{Considerações finais}

A proposição do diálogo entre as referências de Paulo Freire e Maurice Tardif convida ao aprofundamento de estudos sobre o valor epistemológico atribuído aos saberes experienciais dos/as educadores/as que atuam na escola e na universidade. Sobretudo, se concordarmos com os autores acerca de que "a relação entre a pesquisa universitária e o trabalho docente nunca é uma relação entre uma teoria é uma prática, mas uma relação entre atores, entre sujeitos cujas práticas são portadoras de saberes" (TARDIF, 2002, p.237), bem como de que "Ninguém nasce educador ou marcado para ser educador. A gente se faz educador, na prática e na reflexão sobre a prática (FREIRE, 1991, p.58).

Com base nestas compreensões, importa referir, ao final deste trabalho, que os estudos realizados não se dissociam da experiência profissional da autora, marcada pelo exercício de articulação universidade escola, em diferentes momentos e de diferentes formas (FREITAS; WAISSMAN, 2001, FREITAS; LIMA, 2006, FREITAS; SALES; SALLET; SCHARDOSIN, 2006, FREITAS; FORSTER, 2016, FREITAS, 2017).

Deste percurso, resulta o emprego da expressão formação com educadores, no lugar de formação de professores, com o intuito de chamar atenção para a horizontalidade das relações estabelecidas entre educadores/as que atuam na universidade, na escola e em outros espaços educativos (FREITAS; MACHADO, 2010). A horizontalidade das relações enquanto perspectiva da formação com educadores/as é expressão do compromisso de traduzir, na prática, o reconhecimento dos/as educadores/as como sujeitos de conhecimento. Nesse sentido, algumas ideias-força vêm se anunciando como reveladoras dos benefícios da articulação universidade escola, no que diz respeito ao fortalecimento dos saberes docentes em seu potencial educativo transformador/libertador.

A ideia-força da pedagogia da pergunta, visto que esta, quando exercida desde a escola básica, contribui significativamente para a construção da autonomia dos educandos, repercutindo em sua atuação futura como acadêmicos/as. Ou seja, a experiência da pergunta na vida escolar apresenta possibilidades de transformação das relações acadêmicas mediante o posicionamento dos próprios educandos e vice-versa, ou 
seja, a experiência da pergunta na formação acadêmica dos educandos é relevante para que se configurem possibilidades a serem recriadas em suas futuras atuações como educadores/as.

A ideia-força do diálogo de saberes como princípio das relações estabelecidas para "fazer a aula" no âmbito da formação com educadores/as, buscando referências em diferentes fontes de conhecimento, credibilizando a escola como um espaço privilegiado de formação e produção de conhecimento, dando visibilidade à experiência profissional dos educadores e educadoras que nela atuam.

A ideia-força do registro como princípio da pesquisa assumido de modo a subverter a lógica dominante do pensar para escrever, por meio do incentivo às práticas de escrever para pensar, tendo em vista apoiar o desenvolvimento das autorias no cotidiano do trabalho docente.

Tais ideias-força, entre outras, configuram possibilidades para o redimensionamento das relações pessoais/institucionais entre universidade e escola, em interface com outros espaços educativos. Com este intuito reitera-se, conforme já referido, o princípio da reciprocidade entre as ações de pesquisar o ensino e de ensinar por meio da pesquisa enquanto referência para problematizar as ações entre universidade e escola, na perspectiva da horizontalidade das relações estabelecidas.

No sentido de sugerir novos diálogos para a continuidade desta reflexão, merecem ser retomadas as referências aos autores que inspiraram a problematização inicial deste trabalho. Com Boaventura de Sousa Santos, ratifica-se a compreensão de que "O princípio a ser afirmado é o compromisso da universidade com a escola pública. A partir daí, trata-se de estabelecer mecanismos institucionais de colaboração através dos quais seja construída uma integração efetiva entre a formação profissional e a prática de ensino" (SANTOS, 2005, p.84). Com Francisco Imbernón, sublinha-se a importância dos contextos educativos concretos para a geração do conhecimento pedagógico. Em suas palavras:

O contato da formação com a prática educativa faz com que o conhecimento profissional se enriqueça com outros âmbitos: moral e ético, além de permitir que se fomente a análise e a reflexão sobre a prática educativa, tentando uma recomposição deliberativa dos esquemas, concepções e crenças que o conhecimento pedagógico tem sobre o ensino e a aprendizagem (IMBERNÓN, 2011, p.121).

Enfim, este é o sentido da horizontalidade das relações que se expressa na proposição da formação com educadores/as enquanto perspectiva a ser perseguida, na 
teoria e na prática. Nesta direção, a continuidade das leituras de Paulo Freire, em diálogo com outros/as autores/as, se faz fecunda de possibilidades.

\section{Referências}

FREIRE, Paulo. A Educação na Cidade. São Paulo: Cortez, 1991.

Pedagogia da Esperança: Um reencontro com a Pedagogia do oprimido. Rio de Janeiro: Paz e Terra, 1992.

Política e educação. SP: Cortez, 1993a.

Professora, sim; tia, não.: cartas a quem ousa ensinar. São Paulo, Olho D’Agua, 1993 b.

Pedagogia da Autonomia: Saberes necessários à prática educativa. São Paulo: Paz e Terra, 1996.

FREIRE, Paulo; Shor,Ira. Medo e Ousadia: o cotidiano do professor. $3^{\text {a }}$ ed. Rio de Janeiro: Paz e Terra, 1986.

FREITAS, Ana Lúcia Souza de. Pedagogia da Conscientização - Um legado de Paulo Freire à formação de professores. Porto Alegre: EDIPUCRS, 2001.

FREITAS, Ana Lúcia Souza de. Saber de experiência feito (VERBETE) In: STRECK, Danilo; REDIN, Euclides; ZITKOSKI, Jaime (orgs.). Dicionário Paulo Freire. - Belo Horizonte: Autêntica Editora, 2008. 2014, v.1.

. Leituras de Paulo Freire: uma trilogia de referência. Passo Fundo, Méritos,

Donald Schön e Paulo Freire: um diálogo fecundo na formação de uma professora-pesquisadora In: SHIGUNOV NETO, Alexandre; FORTUNATO, Ivan. 20 anos sem Donal Schön: o que aconteceu com o professor reflexivo? São Paulo: Edições Hipótese, p.116 a 137, 2017. Disponível em: < https://drive.google.com/file/d/0B4VVtZy9vhzvY31EaFJnTXEwSnM/view>

Acesso: 16/4/2017

FREITAS, Ana Lúcia Souza de.; FORSTER, Mari. Paulo Freire na formação de educadores: contribuições para o desenvolvimento de práticas crítico-reflexivas. Educar em Revista, Curitiba, Brasil, n. 61, p. 55-69, jul./set. 2016. Disponível em:

< http://www.scielo.br/pdf/er/n61/1984-0411-er-61-00055.pdf $>$ Acesso: 16/4/2017

FREITAS, Ana Lúcia Souza de; MACHADO, Maria Elisabete.

Formação com educadores/as e os desafios da práxis da Educação Popular na Universidade. Educação, Porto Alegre, v.33, n.2, maio/ago. 2010. Disponível em:

$<$ http://revistaseletronicas.pucrs.br/ojs/index.php/faced/article/view/7348 >Acesso: $16 / 4 / 2017$

FREITAS, Ana Lúcia Souza de; MACHADO, Maria Elisabete; JULIANE, Sílvia Juliana Baptista. O Diário de Pesquisa na articulação da Universidade com a Escola. RESUMO. In: XV Fórum de Estudos: Leituras de Paulo Freire. Taquara, FACCAT, 2013. ANAIS. 
FREITAS, Ana Lúcia Souza de; LIMA, Cleiva Aguiar de.(Trans)formações de saberes e fazeres docentes na escola e na universidade. In: VII Fórum de Estudos: Leituras de Paulo Freire. Passo Fundo, UPF, 2006. ANAIS.

FREITAS, Ana Lúcia Souza de; SALES, Caroline Martins Pereira de; SALLET, Fabiana Machado; SCHARDOSIM, Jaqueline Silveira. O cotidiano escolar como espaço de formação e transformação profissional: desafios à atuação supervisora pesquisadora. Espaço Inovação: Revista Pedagógica / Associação dos Supervisores de Educação do Estado do Rio Grande do Sul - Porto Alegre: ASSERS, v.5, p.26 - 29, 2006.

FREITAS, Ana Lúcia Souza de; WAISSMAN, Carla Jeane Coelho. Projeto Sonho Possível: Vivências De (Trans)Formação Permanente E Reinvenção Da Escola In: III Fórum de Estudos: Leituras de Paulo Freire. Canoas,UNILASSALE, 2001. ANAIS.

GAUTHIER, Clermont [et al.] Por uma teoria da Pedagogia. Pesquisas contemporâneas sobre o saber docente. Tradução: Francisco Pereira. - Ijuí: Ed. UNIJUÍ, 1998. (Coleção Fronteiras da Educação).

IMBERNÓN, Francisco (org.). A Educação no século XXI: os desafios do futuro imediato. Tradução Ernani Rosa - 2a ed. - Porto Alegre: Artes Médicas Sul, 2000.

. Formação Docente Profissional: formar-se para a mudança e a incerteza. $4^{\mathrm{a}}$ ed. São Paulo: Cortez, 2011.

SANTOS, Boaventura de Sousa. A Universidade no século XXI: para uma reforma democrática e emancipatória da Universidade. - São Paulo: Cortez, 2005 (Coleção questões da nossa época; v.120).

SCHÖN, Donald A. Educando o profissional reflexivo: um novo design para o ensino e a aprendizagem. Tradução Roberto Cataldo Costa - Porto Alegre: Artes Médicas Sul, 2000 .

TARDIF, Maurice. Os professores enquanto sujeitos do conhecimento: subjetividade, prática, e saberes no magistério. CANDAU, Vera Maria (org.). Didática, currículo e saberes escolares. - Rio de Janeiro: DP\&A, 2002a.

Saberes docentes e formação profissional. - Petrópolis, RJ: Vozes, $2002 b$.

A profissionalização do ensino passados trinta anos: dois passos para a frente,

três para trás. Revista Educ. Soc., Campinas, v. 34, n. 123, p. 551-571, abr.-jun.

2013. Disponível em: 〈http://www.scielo.br/pdf/es/v34n123/fr_13.pdf > Acesso:

$16 / 4 / 2017$.

Submetido em: 20-05-2017.

Publicado em: 01-06-2017. 